\section{El cuerpo humano en el "Moisés" de Miguel Ángel}

\author{
GUSTAVO FIGUEROA
}

\section{The human body in Michelangelo’s Moses}

What grips us so powerfully to a work of art is the artist's intention, if he succeeds to express it in his work and we are able to understand it. Michelangelo's Moses established the essential structures of an animate organism and the embodiment of consciousness in the world. Since the body is an expressive unit, it is possible to reconstruct a highly feasible sequence of movements that might have preceded the moment caught in the statue. It is an expression of the highest ideal of mental and spiritual achievement through the controlled tension between action and restraint. The phenomenon of embodiment and feeling the body as own is the basis of concrete human existence.

(Rev Med Chile 2013; 141: 1321-1326).

Key words: Anatomy, artistic; Human body; Psychology; Sculpture.

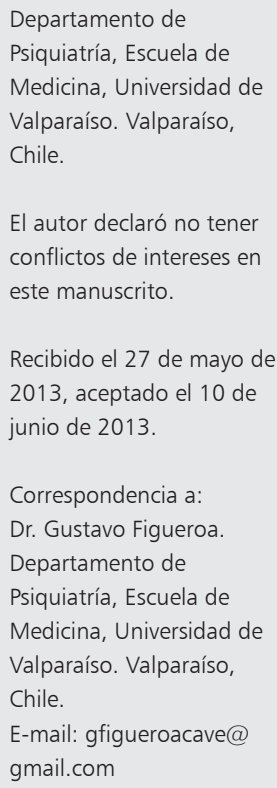

L o que nos coge poderosamente en una obra de arte es la intención del artista, en la medida en que tiene éxito al expresarla en su obra y dárnosla a entender. El “Moisés” de Miguel Ángel estableció las estructuras esenciales del organismo animado, de la corporalidad de la conciencia en el mundo. A partir de un análisis detallado de la figura es posible reconstruir una secuencia altamente posible de movimientos que podrían haber precedido el momento captado por la estatua, porque su cuerpo es una unidad expresiva o un cuerpo-experimentado. Es la expresión del más alto ideal de un rendimiento mental y espiritual por medio de la tensión controlada entre acción y restricción. El fenómeno de la corporalización, del cuerpo-propio, es la matriz de la existencia humana concreta.

El cuerpo humano constituye el objeto propio de la medicina. Desde que se convirtió en ciencia (tekhné iatriké) en Grecia, aparece ya inequívocamente en el escrito hipocrático de prisca medicina: sólo "podrá alcanzarse un conocimiento exacto... en [la sensación de] el cuerpo"'. La medicina lo ha estudiado empírica, objetiva y constrastablemente con su método y sus resultados superan cualquiera expectativa ${ }^{2}$. Pero Heidegger ${ }^{3}$ señala que la ciencia es " $<$ una $>$ de las maneras posibles de conocer" la realidad y, si nos atenemos sólo a ella, no captaremos la realidad en su totalidad. Y agregó: el arte des-cubre (Unverborgenheit) lo en-cubierto, trae-a-presencia lo que está oculto de una manera no objetivante o cosificadora; es la verdad artística que, a diferencia de la verdad científica, deja-ser a los fenómenos "proporcionándonos las condiciones para una pregunta auténtica acerca de quién sea el hombre [corpóreo]" 4,5 .

El cuerpo humano representa un eje decisivo en la imponente producción artística de Michelangelo Buonarroti (1475-1564). Sus pinturas y esculturas despliegan de modo tan determinante las casi infinitas posibilidades de expresión y sentido del cuerpo, que se puede afirmar que su creación es la respuesta al enigma fundamental de la condición humana: ser hombre radica en ser carne espiritualizada-sujeto corpóreo impulsado por lo superior ${ }^{6,7}$. El "Moisés" es una escultura privilegiada no sólo porque la corporeidad resplandece con una riqueza de significados pocas veces conseguida en el Renacimiento, sino porque estos significados se dan en una unidad de sentido que supera su heterogeneidad y disparidad.

El trabajo estudiará el "Moisés" en tanto ilumina la condición corporal como experiencia radical del ser humano. Primero lo investigaremos como 
expresión de su pertenencia al género humano. Luego indicaremos cómo, por debajo de lo compartido y común a lo humano, se adentra en la intimidad única, irrepetible y propia de "Moisés". O sea, antropología y fenomenología del cuerpo.

\section{La estatua "Moisés"}

Miguel Ángel llevó a cabo una doble revolución artística en la figura. Por un lado, a la belleza clásica griega, hierática e imponente, la dinamizó a través de movimientos y actos, haciéndola adquirir una vitalidad nunca antes lograda; así, desestimó como demasiado estáticas la concepciones de Dürer y Vesalio, puesto que no se ajustaban a lo que él aspiraba: apasionamiento, frenesí, arrebato, furia. Por otra, sus disecciones en cadáveres para el estudio de órganos no fueron menos sistemáticas y originales que las de Leonardo, Vesalio, Falopio, de modo que enfermó del estómago mientras trabajó en la elaboración de un texto sobre teoría de la anatomía, que nunca terminó ${ }^{8,9}$.

El "Moisés" fue ejecutado para la tumba del papa Julio II. Del monumento se conocen seis versiones entre 1505 y 1545, y Condivi y Vasari ${ }^{10,11}$ aseveran que sufrió innumerables modificaciones durante su dramática elaboración, como productos de intrigas, codicias y litigios con papas y albaceas hasta su término; el "Moisés" conservó su diseño original, aunque su ubicación física y esculturas acompañantes variaron sustancialmente en acuerdo a los distintos proyectos arquitectónicos ${ }^{12}$.

\section{Antropología del cuerpo del "Moisés"}

Laín Entralgo ${ }^{6}$ señaló que en Miguel Ángel el cuerpo posee tres dimensiones: cuerpo carnal, personal y espiritual. Se puede entender el "Moisés" siguiendo estas agudas directrices, aunque profundizando en sus particularidades específicas ${ }^{1}$. Su cuerpo carnal impacta y se impone de inmediato: es naturaleza en la acepción más orgánica de la palabra- músculos, tendones, nervios, fuerza física. Pero no es anatomía descriptiva propia de cirujanos, ni menos un templo estático carente de pulsiones o deseos; todo lo contrario, es cuerpo colmado por un combustible interior que lo inflama e impulsa, impresionando como impetuoso y pura reciedumbre. Carne particular- mente sensible aunque no receptiva, activa y presta para abalanzarse. La omnipotencia de sus pasiones desata fuerzas elementales, la indignación y la ira hacen de su cabellera una llamarada, los miembros y la barba "son rocas, es decir, la tierra misma", su figura de coloso tiembla de indignación, "es un cataclismo humano". Exhibe sin pudor sus poderosos bíceps ante los demás, que no es ostentación sino sello de su torbellino y la violencia que lo ahoga ${ }^{2}$. Inversamente, su cuerpo personal trasciende su condición natural cósmica y señala un dentro, una intimidad o persona. Los dos lados de la estatua manifiestan su interioridad en lucha o rivalidad; el de la izquierda es "el lado de las fuerzas del mal contra las que se rebela", el derecho, "la estabilidad consciente en que se apoya"; vale decir, en su corporalidad se despliega "el nacimiento de la pasión, su clímax y el ocaso final”. Por lo cual la masa de músculos, tendones y gestos se transfigura en personalización entendida en una doble vertiente: como aceptación insoslayable del destino y como expresión de su contradictoria personalidad ${ }^{3}$. Por fin, como cuerpo espiritual se desnuda "en el supremo desdén por la depravación humana”, se rebela por la incapacidad del hombre de aspirar y mantener una misión superior, por la radical indigencia de espíritu que anida en el fondo de nuestro ser. Cuerpo que se eleva por sobre su carne puramente cósmica, por sobre su personalización intransferible y adquiere rasgos supraterrenales, aunque todavía persevera afirmado, aferrado o enraizado en la naturaleza.

Tolnay ${ }^{8}$ ha intuido al "Moisés" aproximadamente de ese modo. De ahí su principal conclusión: "Moisés es aquí el símbolo de una actitud eterna, no la reproducción de un determinado momento de su vida": "la cólera justa de un ser superior frente a un mundo mostrenco".

\section{Fenomenología del cuerpo de "Moisés"}

¿Es cierto que el Moisés es el símbolo de una actitud esencial y permanente del ser-hombre? ¿Es efectivo que no revela un instante preciso del profeta?

Tres advertencias previas. Por un lado, la palabra cuerpo deriva del griego, karpós, que significa fruto, simiente, envoltura; como fruto, es paradójico, porque implica una finalidad o télos de madurez y también una simiente contenida. Pero, 
Platón ${ }^{13}$ señaló los variados sentidos del cuerpo como sôma: tumba (sêma), cárcel (sêma) y signo (sema), porque desde los pitagóricos el cuerpo es cuerpo-tumba o cuerpo-cárcel al que el hombre se halla de por vida prisionero. Por otro, omitiremos cualquier referencia a la convulsionada historia del diseño de la tumba de Julio II y la ubicación del Moisés en su interior, aunque implique la crítica de historiadores del arte que sostienen que la estatua sólo alcanzaría su sentido pleno al interior del monumento ${ }^{14-17}$. Por último, esto impone atenerse a su figura; esta abstención metodológica rigurosa al phainomenon Moisés se llama fenomenología: poner de manifiesto el fenómeno sólo en tanto es manifiesto, poniendo entre paréntesis (epoché) cualesquier concepción o tesis por muy justificadas que parezcan ${ }^{18-20}$.

Durante los veranos de 1901, 1912 y 1913 Freud $^{21,22}$ pasó semanas contemplando pasmado al titán judío por su incapacidad para penetrar en su misterio, hasta que se le hizo la luz; sin saberlo, aplicó el método fenomenológico con sus reglas básicas: variación imaginaria, intuición de esen$\operatorname{cias}^{23}$. Pero su descubrimiento quebrantó su existencia: lo precipitó en un profundo autoanálisis y desde entonces Moisés jamás dejará de intrigarlo hasta el final de sus días ${ }^{24-29}$. ¿Dónde reside lo fascinante? porque, para Freud, resulta indudable que el cuerpo revela que acaba de descender del Sinaí y contempla a su pueblo adorando al becerro de oro.

\section{El cuerpo vital}

De inmediato se impone que la palabra alemana Körper-cuerpo anatómico, físico, objetivo-no corresponde al "Moisés", sino Leib-cuerpo viviente, propio $^{30-33}$, fuerza vital de la cual emana y se nutre su existencia. Su figura no es exclusivamente plasticidad -pura presencia- sino una figura expresiva, donde expresividad apunta a que toda su postura y gestos tienen una función transitiva: comunicar su intimidad afectiva. Su cuerpo denuncia su subjetividad: ademanes, expresiones y atuendos señalan una rica vida interior en efervescencia. La pierna derecha se apoya firme en el suelo con todo el pie mientras la izquierda la hace sólo con dos dedos; ambigua postura porque, más que pronta para abalanzarse hacia adelante, parece que está vacilante retrocediendo hacia su butaca. El torso también insinúa estar reculando y los poderosos brazos se retiran hacia sí; el izquierdo se desprende del abdomen inferior, quizás asiento de las pasio- nes; el derecho ejecuta una doble acción: sus dedos índice, medio y meñique permiten que escurra su densa barba con suavidad y con su antebrazo aprieta contra su costado las dos Tablas de la Ley, que están en posición invertida e impresionan como inestables o en peligro de caer. Su cabeza gira violentamente hacia su izquierda arrastrando su barba y su mirada, de ceño fruncido, con asombro, fulmina lo que está ante sus ojos; unos labios de comisuras algo caídas revelan una rabia amarga llena de desdén. Vitalidad estremecida y ardiente, colmada de emociones y anhelos, de angustia y desazón, de pasión crispando sus músculos y miembros, de tensiones que se delatan en las contradicciones entre las diferentes zonas.

\section{El cuerpo propio}

Los ojos no miran a la humanidad sino a su pueblo que lo hiere en lo más profundo, su núcleo personalísimo está vertido hacia esta visión de la traición pero sin perder el control de sus Tablas, aunque estas estén ubicadas en la periferia de su atención. Es el momento de la decisión: incorporarse y romper con furor las Tablas inundado por su menosprecio o, contrariamente, retroceder y permanecer en su asiento en consideración a la misión superior que le está asignada. Su precipitado dolor inicial experimentado en lo más profundo de su bajo vientre comienza a calmarse, lo mismo que el espasmo con que cogió su barba empieza a distenderse y sus tres dedos se deslizan con suavidad entre los bucles. Es su voluntad férrea la que actúa y coordina sus acciones, cada segmento de su cuerpo delata que él es autor autoconsciente y protagonista. Su inclinación violenta que irrumpe de su vitalidad desaforada es atemperada por el núcleo de su ser, que está dirigiendo y recordando su cometido supremo. Es el cuerpo entero fragmentado en el momento decisivo de la resolución, es su libertad la generadora de este acto propio y único, es el instante puro. 3. El cuerpo narrativo. La mirada fulgurante se proyecta más allá del populacho hacia el futuro que le está asignado, el brazo que aprieta las Tablas para que no se caigan asume la tradición milenaria que acaba de ser renovada arriba en la solitud del Sinaí, las vestiduras que lo envuelven evidencian su propia biografía de compromiso personal con Dios y su fe. La pierna derecha ya no está presta a saltar en el momento siguiente sino retrocede hacia su trono desandando lo insinuado. En otras palabras, el 
instante presente se lanza hacia su porvenir desde donde vuelve sobre sí y coge su pasado entero. Pasado, presente y futuro: es su identidad personal y como tal es una identidad narrativa; por ello, está contada meticulosamente en las disposiciones de sus manos, miembros, ropajes, barba ${ }^{34}$. Es la retroo-pro-referencia (Rück-oder-Vorbezogenheit) del hombre de que habla Heidegger ${ }^{35}$. Modificando las intenciones de Zubiri ${ }^{36}$, el Moisés es cuerpo como agente, autor y actor: naturaleza, libertad y destino, o sea, ejecución, decisión y destinación.

¿Qué develó el cuerpo del "Moisés" a Freud? Recién baja del monte Sinaí y la ira lo consume ante la visión de su pueblo venerando al becerro de oro. A punto de levantarse y despedazar las Tablas, anegado por el sufrimiento y menosprecio, coge sus barbas con furor; en el último momento-"lapaz-antes-de-la-tormenta"-súbitamente recuerda su misión superior. Esta iluminación lo devuelve a su cometido supremo y lo reasume, lo que lo lleva a retroceder a su trono y relajar sus brazos, dedos, tronco. Intuyendo que las Tablas están a punto de caer al suelo, retorna sobre su flanco y las aprieta con dificultad. Vale decir, en comparación al iracundo Moisés bíblico que despedazó las Tablas, el de Miguel Ángel es su opuesto: un ser soberano, representa el triunfo de lo espiritual del hombre sobre sus propias pasiones terrenales; es la voluntad que jamás claudica, jamás se somete aunque esté inundada por la aflicción y desdén, la que aspira a algo suprahumano porque nunca desconoce ni elude la misión prioritaria, aquella que se asume consigo mismo y con la trascendencia.

\section{El cuerpo de la revelación}

¿Y si el Moisés no correspondiera a la primera sino a la segunda bajada del Sinaí, al capítulo 34 y no 32 del Éxodo, al encuentro con la divinidad según Deuteronomio 31? ¿Qué habla el cuerpo en favor de esta posibilidad?

\section{El cuerpo fisiognómico}

Lo central es la apariencia ante el otro, el aspecto, la postura, los límites y la distancia, la confianza y el abrirse ${ }^{37}$ : dos cuernos nacen desde su frente. Una mala traducción tanto de la versión hebraica como de la Vulgata del texto sagrado -cuerno o $\mathrm{ka}$ ran significa tanto cornuta esset facies sua como su rostro irradió una luz- puede inducir a error ${ }^{38,39}$. La luz resplandece desde su cara: su semblante vuelto hacia el lado izquierdo observa pasmado su propia irradiación producto del reflejo enceguecedor de Dios sobre él, incrédulo, sobrecogido, espantado, asombrado-mirar y ser mirado. El talante y su posición erecta, su apariencia denuncian su confianza-desconfianza al exponerse ante la divinidad misma, la cercanía e intimidad se vuelven aterradoras y numinosas ${ }^{40}$. El asirse las barbas es símbolo inequívoco de veneración y sumisión ante su Creador. El manto que había cubierto su cabeza como distintivo de su devoción yace sobre su pierna derecha, como si ahora estuviera en otro momento del encuentro con Dios; las Tablas ya las ha escrito y conoce bien su contenido, por lo que son desatendidas bajo su brazo. El mensaje es otro y proviene actualmente de Dios mismo. Este nuevo mensaje le hace cogerse el abdomen donde se asientan las pasiones más profundas, desconectarse de lo que estaba hablando con su pueblo y retroceder de pura emoción hacia su trono.

\section{El cuerpo asumido}

Su mirada sobrecogida por la visión de Dios, que le hizo girar la cabeza con presteza hacia la izquierda, está cercada por un ceño que delata que, simultáneamente, escudriña su interior meditando las consecuencias generadas por el mensaje, quizás de incredulidad y temor. Su cuerpo entero se inclina hacia atrás y los brazos estrechan su tronco y barbas, como guardando para sí todas sus energías dentro de su propia corporalidad, aunque relajando la tensión del momento anterior cuando comenzó a escuchar las primeras palabras de Dios. No pierde el control de piernas ni manos pero estas adquieren un valor subordinado ante el discurso divino; su cuerpo sigue siendo todo suyo aunque sin prestar ninguna función en este instante único: es vivido pero no vivenciado.

\section{El cuerpo existencial}

Si algo caracteriza al "Moisés" es su ek-sistencia: estar-fuera-de-sí, ser-más-allá-de-sí ${ }^{18}$. El coloso está pro-yectado hacia aquello que las palabras de Dios le están comunicando. Ya tiene las Leyes junto a sí, conoce las instrucciones para su recta interpretación, sabe de la infidelidad y traición de su pueblo mientras él estaba arriba en el monte, pero desconocía lo último y que ahora está recibiendo y asimilando: el mensaje final -él no entrará en la tierra prometida, su muerte está muy pronta. 
Su longeva edad no se trasluce en su hercúlea apariencia, pero la voluntad de Dios es el hecho de los hechos. Sus fuerzas titánicas le ayudarán para impulsar a su gente pero le serán insuficientes para ingresar en el terruño añorado, como lo experimenta con aflicción, dolor y melancolía en sus entrañas. Triunfo y derrota, plenitud de potencia y resignación impotente, alegría suprema y conmoción insuperable.

¿Qué propone el cuerpo de la revelación? Es el cuerpo del profeta visionario iluminado por el encuentro último en la tierra con la divinidad. $\mathrm{Su}$ vida trascurrida se da a conocer en su lado derecho: la fidelidad absoluta a su credo, las instrucciones que debe dejar como legado a su pueblo para la correcta interpretación de la palabra, las penurias por el desengaño sufrido por la liviandad y volubilidad de sus seguidores. Su cuerpo izquierdo recibe el impacto más feroz jamás esperado, las tareas más allá de toda comprensión humana, esto es, conducir a su pueblo sin entrar en la tierra prometida y morir como hombre de fe acatando sin preguntar. Culminación de vida e inminencia de la muerte.

\section{El cuerpo humano}

1) El cuerpo humano de la medicina es producto de datos empíricos contrastables de manera sistemática, progresiva, que dan origen a teorías sometidas a reglas cada vez más precisas y compatibles con el grueso de los conocimientos relevantes.

2) A pesar de la unidad del cuerpo, éste posee un exceso de sentido, es una experiencia humana con significación múltiple y expresión multívoca y la medicina se circunscribe, por ser consecuente con su método, a unos pocos sentidos, aquellos que entregan certeza.

3) La obra artística revela otros sentidos que saturan al cuerpo del hombre, más originarios, más primarios, más inmediatos, aunque también sin agotarlos por completo. Representa otro camino en la apropiación de la verdad del cuerpo, camino que intuye directamente sin ser constreñido por un método único y que se traduce en multitud de visiones, perspectivas o escorzos.

4) El "Moisés" de Miguel Ángel denuncia que el cuerpo humano es una realidad que no es homogénea sino compuesta de estratos -tiene una tópica- que refleja los planos de su ser: vitalidad, propiedad y narratividad. La unidad que lo hace comprensible proviene de su proyecto de vida personal e intransferible que se matiza y da a conocer en estos estratos.

5) Aún así, al "Moisés" le es inherente también un exceso de sentido que no se satisface con tres interpretaciones: es tarea de cada investigador apoderarse e iluminar otras significaciones.

6) Las tres interpretaciones rivales investigadas desde el cuerpo hacen patente el significado inabarcable de lo humano. El "Moisés" representante de lo superior frente a la medianía, el que lucha para vencer lo pasional fugaz en aras de lo noble trascendente y el que sabe que la vida consiste en llevar a cabo una misión, pero acatando su radical finitud que lo acosa desde su nacimiento. ¿Tres Moisés o la identidad narrativa de Moisés que es única y múltiple simultáneamente?

\section{Referencias}

1. Hipócrates. De la medicina antigua. México: Universidad Autónoma de México, 1991.

2. Laín Entralgo P. El cuerpo humano. Teoría actual. Madrid: Espasa-Calpe, 1989.

3. Heidegger M. Das Ding. En: Heidegger, M. Vorträge und Aufsätze. 5. Aufl. Pfullingen: Neske, 1967. p. 157-75.

4. Heidegger M. Der Ursprung des Kunstwerkes. En: Heidegger M. Gesamtausgabe 5. Frankfurt: Klostermann, 1984. p. 7-68.

5. Heidegger M. Wissenschaft und Besinnung. En: Heidegger, M. Vortäge und Aufsätze. 5. Aufl. Pfullingen: Neske, 1967. p. 41-66.

6. Laín Entralgo P. Miguel Ángel y el cuerpo humano. En: Laín Entralgo, P. Teatro del mundo. Madrid: Espasa Calpe, 1986. p. 86-104.

7. Mariani V. Michelangelo the painter. New York: Harry N. Abrams, 1964

8. Tolnay Ch. de. Miguel Ángel. Escultor, pintor y arquitecto. Madrid: Alianza, 1985.

9. O’Malley CD. Los saberes morfológicos en el Renacimiento. La anatomía. En: Laín Entralgo, P, director. Historia universal de la medicina. Tomo IV. Medicina moderna. Barcelona: Salvat, 1973. p. 43-77.

10. Condivi A. The life of Michelangelo. Baton Rouge: Louisiana State University Press, 1975.

11. Vasari G. Lives of the most eminents painters, sculptors and architects. New York: Random House/Modern Library, 1959. 
12. Tolnay Ch. de. Michelangelo IV. The tomb of Julius II. Princeton: Princeton University Press, 1954.

13. Platón. Crátilo. En: Apología de Sócrates, Menón, Crátilo. Madrid: Alianza, 2004. págs. 171-217.

14. Satzinger G. Michelangelos Grabmal Julius' II. in S. Pietro in Vincoli. Z f Kunstgesch 2001; 64: 177-222.

15. Echinger-Maurach C. Studien zu Michelangelos Juliusgrabmal. 2 Bände. Hildesheim: Georg Olms, 1991.

16. Echinger-Maurach C. Michelangelo`s monument for Julius II in 1534. Burligt Mag 2003; CXLV: 336-44.

17. Frommel Ch. L. Michelangelos's Moses and the tomb of Julius II at St. Peter in Chain. htpp://www.progettomose. it/eng/pdf/frommel.pdf. 1-15.

18. Heidegger M. Sein und Zeit. 10. Aufl. Tübingen: Niemeyer, 1963.

19. Husserl E. Phänomenologische Psychologie. Vorlesungen Sommersemester 1925. 2. Aufl. Haag: Nijhoff, 1968.

20. Figueroa G. La psicología fenomenológica de Husserl y la psicopatología. Rev Chil Neuro-Psiquiatr 2008; 46: 224-37.

21. Freud S. Der Moses des Michelangelo. Gesammelte Werke X. Frankfurt: S. Fischer, 1914. p. 171-201.

22. Freud S, Ferenczi S. Briefwechsel. Band I/2. Wien: Böhlau, 1993.

23. Husserl E. Cartesianische Meditationen und Pariser Vorträge. Zweite Auflage. Husserliana I. Den Haag: Martinus Nijhoff; 1973.

24. Freud S. Nachtrag zur Arbeit über den Moses des Michelangelo. Gesammelte Werke XIV. Frankfurt: S. Fischer, 1927. p. 319-22.

25. Freud S. Der Mann Moses und die monotheistische Religion. Gesammelte Werke XVI. Frankfurt: S. Fischer, 1939. p. 101-247.

26. Grubrich-Simitis I. Freuds Moses-Studie als Tagtraum. Frankfurt: S. Fischer, 1994.

27. Grubrich-Simitis I. Michelangelos Moses uns Freuds
<Wagstüsck>. Eine Collage. Frankfurt: S. Fischer, 2004.

28. Yerushalmi YH. Freud's Moses; judaism terminable and interminable. New Haven: Yale University Press, 1991.

29. Goldsmith GN. Freud's aesthetic-response to Michelangelo’ Moses. Ann Psychoanal 1992; 20: 245-69.

30. Ortega y Gasset J. Vitalidad, alma, espíritu. Obras Completas. Tomo II. Madrid: Revista de Occidente, 1963. p. 451-80.

31. Scheler M. Wesen und Formen der Sympathie. En: Frings S, Hrsg. Gesammelte Werke. Band VI. Bern: Francke, 1973.

32. Figueroa G. Cuerpo y corporalidad. En: Figueroa G, Behar R. Trastornos de la conducta alimentaria. 2. Edición. Santiago: Mediterráneo, 2010. p. 39-50.

33. Husserl E. Zur Phänomenologie der Intersubjektivität. Texte aus dem Nachlass. Dritter Teil. 1929-35. Den Haag: Martinus Nijhoff, 1973.

34. Ricoeur P. L'identité narrative. En: Bühler, P, Habermacher, JF, editeurs. La narration. Quand le récit devient communication. Genéve: Labor et Fides, 1988. p. $287-$ 300 .

35. Heidegger M. Prolegomena zur Geschichte des Zeitbegriffs. Marburger Vorlesung Sommersemester 1925. Gesamtausgabe 20. Frankfurt: Klostermann, 1994.

36. Zubiri X. Sobre el hombre. Madrid: Alianza, 1986.

37. Zutt J. Über Daseinsordnungen. En: Zutt, J. Auf dem Wege zu einer anthropologischen Psychiatrie. Berlin: Springer, 1963. p. 310-29.

38. Verspohl F. Der Moses des Michelangelo. STädel-Jahrbuch: 1999: 13: 155-76.

39. Reik, T. Probleme der Religions psychologie. I. Teil: Das Ritual. Lepzig: Internationaler Psychoanalytischer Verlag, 1919.

40. Otto, R. Das Heilige. Über das Irrationale in der Idee des Göttlichen und sein Verhältnis zum Rationalen. München: CH Beck, 2004. 